\title{
Huawei’s Business Goal
}

A company must first have a clear business goal. Huawei's business goal is to make itself more competitive, build trust among its customers, and survive market competition. These are actually the most basic goals of any enterprise. Without any of the three, an enterprise will find it hard to survive. An enterprise should first ensure that its most basic goals are continuously achieved, rather than seeking to meet a certain target or maximize the interests of a certain group. In reality, any attempt to maximize interests will yield the opposite result.

Huawei pursues sustainable and profitable growth, rather than maximizing the interests of its shareholders or employees. Huawei only exists to serve its customers. Financially speaking, this refers to the value created for the company. For Huawei, a non-public company, value is not the same as capital market valuation. Rather, it relates to the deeper essence of value, reflecting the company's current and potential capabilities to make profits.

At Huawei, sustainable and profitable growth first means that business performance is robust, with profitable revenue, healthy cash flow, and light assets. Second, sustainable and profitable growth means the company is constantly enhancing its core competencies. Third, it means building a healthy and friendly business ecosystem. Business performance must be steady and balanced if it aims to support the company's long-term survival and development. Huawei's business model is one that maintains a longterm state of hunger for the company and doesn't seek to make big money. 
Huawei does not overly focus on profits. Rather, it adopts a long-term perspective for company development and pursues rapid growth at a reasonable profit rate. Growth is fundamental to any enterprise. In the information and communications industry, you either take the lead or get wiped out. There are no other paths.

All cooperation between people is actually about value sharing. Huawei stresses that every factor of production should be rewarded according to the value it creates for the company. If a certain factor of production is not rewarded, it will become a factor that constrains value creation. Value sharing that is based on the capital and labor invested is what drives Huawei's ongoing growth over the years. Today, this value sharing mechanism is gradually extended to also include its customers and suppliers. This has propelled the entire ecosystem into a positive cycle.

How can everyone at a company, from the founder to each ordinary employee, feel the pressure of market competition, think what customers think, and address what customers are most concerned about? This might be the biggest challenge for enterprise management. That's why an enterprise needs to transfer market pressure to every employee to keep the entire organization vibrant. This is Huawei's management philosophy placing itself in a desperate position in order to survive.

This chapter thoroughly describes the major ways that Huawei adopts to achieve sustainable and profitable growth.

\subsection{Pursuing Sustainable and Profitable Growth \\ 1.1.1 Seeking to Survive as a Legal Entity Beyond Life-Span Constraints of Natural Persons}

We are currently considering how we can develop the company comprehensively. At present, we rely heavily on technology, capital, and individual employees. As we move forward, we need to reduce this reliance in order to shift from the realm of necessity to the realm of freedom. (Ren Zhengfei: Victory Is Inspiring Us, 1994)

The purpose of drafting The Huawei Charter is to help establish rules and regulations, ultimately ensuring the company's sustainable development. This means that the company's development doesn't rely on any 
one individual; this is the only way for Huawei to have a future. (Ren Zhengfei: Minutes of the CEO's Staff Team ${ }^{1}$ Meeting, 1997)

Our company must continue to survive, yet the law of nature indicates that all men eventually die. Even if it is not constrained by the law of nature, a legal entity is still constrained by social norms. Even if a person is not successful, he or she may still live a long life. An enterprise, however, cannot survive for even a week if it lacks key capabilities. If an enterprise can adapt to both the law of nature and social norms, it may survive for centuries. (Ren Zhengfei: Survival Is Fundamental to an Enterprise, 2000)

The survival of an enterprise depends on the enterprise itself. If it does not survive, it is not because others do not allow it to - it is because it cannot find a way to carry on. Survival doesn't mean dragging out an ordinary existence or simply existing for the sake of existing. To survive is not easy and to thrive is even more difficult. This is because we face a constantly changing environment and a highly competitive market. This is further complicated by interpersonal relationships within our company. An enterprise can survive only if it is constantly improving. (Ren Zhengfei: Survival Is Fundamental to an Enterprise, 2000)

The goal of any enterprise is to make itself more competitive, build trust among its customers, and survive market competition. (Ren Zhengfei: Deepening Our Understanding of the Corporate Culture of Staying Customer-centric and Inspiring Dedication, 2008)

Achieving sustainable growth is the biggest challenge that all companies face. To overcome this challenge, we need to identify the major driving forces behind Huawei's development, and figure out how to sustain and improve these forces. Now, people are beginning to understand that a company's core values are what power the joint efforts of all employees. We need to ensure that our successors embrace our core values, and take the initiative to grow by reflection. We need to mold our successors through our core values. This is necessary to ensure the sustainable growth of our company. (Ren Zhengfei: Managers Should Live and Pass on Huawei's Core Values - Speech at the First Workshop on Human Resource Management Outline, Huawei Executive Office Speech No. [2010] 009)

\footnotetext{
${ }^{1}$ Staff Team, or ST for short, is a daily business coordination and decision-making team which operates with the CEO being responsible for the decisions made through collective discussions. Currently, there are STs in business departments and functional departments of the company.
} 
Although a company's survival depends on many different factors, I think that maintaining sustainable and profitable growth and providing quality services are the most important. (Ren Zhengfei: Speech and Comments at the Carrier Network BG's Strategy Retreat in Huizhou, Huawei Executive Office Speech No. [2012] 010)

Whether or not Huawei is an Internet company is not important. Whether or not the Huawei spirit can be called an "Internet spirit" is not important, either. What matters most is whether the Huawei spirit can help us survive. The tortoise as described in the fable titled A Tortoise and a Hare is determined to move forward, doesn't hesitate, and doesn't rely on others. Similarly, we must have a firm belief in our own values, and adhere to development at a reasonable rate. We must not envy others for their rapid success. (Ren Zhengfei: Applying the Spirit of the Tortoise to Catch up with the Dragon Spacecraft-Speech at Huawei Annual Management Conference 2013, Huawei Executive Office Speech No. [2013] 255)

In the future, we will adopt a business model that allows us to maintain our own advantages, strengthen openness and collaboration, and ensure sustainable profitability. Survival is the ultimate victory. Our business model should ensure that we continuously make profits. This doesn't necessarily mean that we earn more than others. Our ultimate goal is to survive. We will firmly hold onto our advantages and continue to move forward. This is what BMW is doing. In addition, we pay sufficient attention to Tesla and learn about its competitive advantages. We should have a positive view of the changes that are taking place worldwide. As long as a strategic opportunity emerges, we will throw sufficient resources to seize it. (Ren Zhengfei: Speech and Comments at the Carrier BG's 2013 Strategy Retreat, Huawei Executive Office Speech No. [2014] 016)

The war-torn days of Genghis Khan are long gone. Modern society is not completely free from chaos, but it will eventually find peace. Survival is the ultimate victory. (Ren Zhengfei: Avoiding Opportunism in the Era of Big Opportunities - Speech at the Luncheon with the Administrative Team of the Consumer BG, Huawei Executive Office Speech No. [2014] 025)

\subsubsection{Huawei Only Exists to Serve Its Customers}

Huawei is not solely focused on profits. We aim for long-term development. We always act with integrity in regards to our customer engagement, operations, and corporate development. It is integrity that helps us 
earn customer satisfaction, trust, and loyalty. By not overly focusing on profits, we can spend more of our energy on diligently pursuing long-term development, rather than on hype or speculation. Admittedly, if we act with integrity and avoid hype, certain customers may not think highly of us, but they will eventually see the value we bring. (Ren Zhengfei: Huawei's Opportunities and Challenges, 2000)

There is only one way to satisfy customers and maintain good customer relationships. That is to provide premium services. This is the basis for Huawei's survival. What does premium service mean? It means customers will continue to praise us even after they have paid us. (Ren Zhengfei: Enlarging Teams to Prepare for a Big Battle, 2000)

Huawei doesn't aim to maximize the interests of its shareholders or employees. Huawei only exists to serve its customers. This is why Huawei has and will continue to succeed. (Ren Zhengfei: Minutes of a Briefing on Marketing Goals, 2002)

Only after customers fully understand us will they realize how we are different from our competitors and see the type of future we can help them create. Then they will buy our products and help us to survive. (Ren Zhengfei: Being Future-oriented, Focusing on Customers' Pain Points, and Displaying Huawei from a Global Perspective, Huawei Executive Office Speech No. [2012] 046)

Huawei's Board of Directors has made it clear that its goal is not to maximize the interests of shareholders or stakeholders (including employees, governments, and suppliers). Rather, it embraces the company's core values of staying customer-centric and inspiring dedication. This is the basis on which Huawei survives. (Ren Zhengfei: Clarifying the Rotating CEO System Under the Leadership of the Board of Directors, 2012)

To provide quality services, we need to allocate high-quality resources to valued customers. This means that after we earn money from a customer, we will invest some of the money back in the customer. How can we do this? By improving our services. (Ren Zhengfei: Remarks at a Briefing by Southeast Africa Multi-country Management Department, Huawei Executive Office Speech No. [2013] 003)

\subsubsection{Inspiring Passion Across the Company Through Steady Growth}

If Huawei had ceased to develop two years ago, we would be cleaning up a mess today and be preparing for bankruptcy. If we cease to develop 
today, we will face the same situation in two years' time. Our competitors are too strong, so we have no choice but to press forward. (Ren Zhengfei: There's No Guarantee for Success, But Boldness Makes a Difference, 1996)

By maintaining growth at a reasonable rate, Huawei provides its employees with opportunities for personal development. Our increasing profits enable us to compensate employees generously and attract global talent. This is how we achieve optimal resource allocation. So, in this sense, a reasonable growth rate is necessary to inspire passion across the company. (Ren Zhengfei: How Long Can Huawei Survive?, 1998)

Huawei must maintain steady growth. So how can we grow faster? The answer lies in management and services. Without effective management, we would not be able to gain traction, and without high-quality services, we would be lost. (Ren Zhengfei: Do Not Be a Temporary Hero, 1998)

As long as we constantly improve upon our core competencies, our market share will increase and we will rise above the rest. Then we can push even further, get even better, and continue to grow. And before you know it, we will have surpassed the competition. (Ren Zhengfei: Focusing on a Down-to-earth Approach to Seize Opportunities for Development, 2000)

Our goal is very clear: We need to develop further. If we don't, we will collapse. (Ren Zhengfei: Human Resources Must Facilitate Business Development and Refrain from Being Rigid, 2008)

\subsubsection{Being an Industry Leader and Leading Industry Development}

We must find our strategic direction amid chaos. Huawei will definitely approach the edge of a cliff one day. What do I mean by this? I mean that we will be ahead of our global peers. No one will then be able to tell us clearly what our future will be and we will have to rely on ourselves to shape the future. It is impossible for us not to approach the edge of the cliff. Nothing good will come out of trying to avoid this situation. (Ren Zhengfei: Remarks at a Meeting at the Shijing Mountain Park in Zhubai, 1997)

In the information and communications industry, you either take the lead or get wiped out. There are no other paths. (Source: The Huawei Charter, 1998)

What do we strive for? We strive to become a global leader and provide quality services to our customers. You might think it sounds funny. How could Huawei have put forward such an ambitious slogan, especially in its 
early years when it was still a small company? However, this goal has enabled us to become what we are today. If we hadn't set this goal, we would have been unable to build customer trust and develop a grand goal while keeping our staff down-to-earth. What people have been and will continue to be concerned about is whether electronic and network products can be upgraded in the future, whether new technology will emerge and develop, and whether the networks they have invested in will be phased out because of technological progress. If Huawei doesn't want to collapse, we must strive to be a global leader. (Ren Zhengfei: How Long Can Huawei Survive?, 1998)

In the future, the global market will be shared by several dominant telecom equipment providers. Huawei's overall strategy is to both compete and cooperate with strong competitors in an ordered and controlled manner to gain a favorable position and firmly counter competitors who aggressively move against us. This is how we can establish a landscape of two or three major players in each segment of the market, namely, regions, products, and customer groups, within the next two years. (Source: Guidelines on Sales Priorities, EMT Meeting Minutes No. [2008] 014)

The First Emperor of the Qin dynasty was able to unify the country after 600 years of chaos because the state finally reached a consensus on their goals and interests. Guan Zhong ${ }^{2}$ said that if all people of a state received income from the same source, that state would stand unrivalled. We must be fully aware of our goals and responsibilities, be resolute in achieving these goals and fulfilling these responsibilities, and at the same time periodically re-examine these goals and responsibilities. We have gathered a team of exceptional talent from each nation. However, in this great era, we have done something that requires great efforts but is not very profitable. Over two decades of hard work, we have established a platform that has tremendous potential value. We must not destroy it because of corruption or lack of resolve. We must hold tight to our oath in the EMT declaration, and at least those 2000 to 3000 people at the core must be strictly self-disciplined. We must remain dedicated and work together towards the same goal and receive income from the same source. (Ren Zhengfei: EMT Meeting Minutes No. [2012] 002)

At best, Huawei can become one of the world's top three players. There is no way we will become the sole global leader. (Ren Zhengfei: Speech and

\footnotetext{
${ }^{2}$ Guan Zhong (c. 720-645 BCE) was a chancellor and reformer of the State of Qi during the Spring and Autumn period of Chinese history.
} 
Comments at the Carrier Network BG's Strategy Retreat in Huizhou, Huawei Executive Office Speech No. [2012] 010)

There are four requirements for being an industry leader. First, a leader needs to be able to envision the future, including the direction, trends, and changes of the industry. But this is not enough. A leader should also be able to shape the future, guiding the entire industry and always playing a leading role. Second, a leader should adopt a value sharing mechanism that covers the entire value chain. If industry players have the opportunity to earn more profits while facing fewer risks, they will be more willing to follow that leader. Why does Apple have so many followers? The company does a huge volume of business. This gives its partners access to a huge market space and a bright future. Apple's high profits mean it can be generous to its suppliers and partners, who are able to earn a lot of money with limited risk. Third, a leader must make trade-offs between what it will and won't do, and remain committed to its choices. Why didn't Ericsson develop WiMAX ${ }^{3}$ ? Because if it had, its followers might not know what it, as a leader, was going to do. If it changes its mind often, its followers may lose confidence in it. Fourth, a leader needs to build an environment that promotes competition and ensures profitability of the entire industry. If a leader snatches up all of the market shares by setting extremely low prices, there will be no room left for other players. (Ren Zhengfei: Speech and Comments at the Carrier Network BG's Strategy Retreat in Huizhou, Huawei Executive Office Speech No. [2012] 010)

To develop our business in the future, we need to lead industry development and serve as an advisor for our customers. (Ren Zhengfei: Speech and Comments at the Carrier BG's 2013 Strategy Retreat, Huawei Executive Office Speech No. [2014] 016)

We must focus on a "needle-tip" strategy for our pipe business, achieve sustainable and profitable growth, and become an ICT leader through peaceful means. (Ren Zhengfei: Speech at the Briefing on HR Work, Huawei Executive Office Speech No. [2014] 057)

To be an industry leader, we must not be so narrow-minded as to throw stones on highways to stop others and develop our own unique strengths. This will harm other market players and impede global progress. This is not what we want to achieve. Our aim is to become an industry leader and

${ }^{3}$ WiMAX, worldwide interoperability for microwave access, also known as "802.16 Wireless Metropolitan Area Network" or "802.16", is an emerging mobile broadband access technology that provides fast Internet connections. 
contribute to the world. Then what makes a leader? Being a leader means making the world a better place, contributing to the broader architecture of global information networks, and sharing benefits with others. Huawei is a large, responsible company. How could we block network information flow? Even if we could, people would still find other ways to reach their destination, and we will be marginalized in the end. (Ren Zhengfei: Speech at a Meeting with Employees of the Legal Affairs Department, Secretariat Office of the Board of Directors, and Wireless Network Product Line, Huawei Executive Office Speech No. [2015] 015)

\subsection{The Meaning of Sustainable and Profitable GrowTH}

\subsubsection{Pursuing Profitable Growth, Healthy Cash Flow, and Light-Asset Operations}

\section{Without economies of scale, it will be increasingly difficult to develop the company}

We are in an information age where, thanks to the widespread exchange of information, human intelligence is enhanced and unleashed on an unprecedented scale. As a result, we can produce more new products and technologies to serve the world. As information networks continue to expand at greater speeds, the lifecycle of new products and technologies will become shorter and shorter. If we can't grasp these fleeting windows of opportunity and achieve economies of scale, we will find it increasingly difficult to develop the company. Without a massive global service network, and a management system to support that network, we won't be able to generate enough profit to survive and maintain rapid development. For Huawei, letting opportunities like this slip can only be attributed to issues with our services and management. This is a strategic inflection point for Huawei. (Ren Zhengfei: Do Not Be a Temporary Hero, 1998)

Due to advances and rapid changes in the information industry, we must achieve economies of scale to shorten the time invested in new products. Scale is an advantage. This advantage is based on effective management. A company that downsizes will become less competitive while a company that scales up but is unable to effectively manage itself will face bankruptcy. Management is an internal factor and can be improved. However, external factors are beyond our control. Small companies, when 
exposed to these factors, will find themselves very vulnerable. To survive, we must continuously improve our management and services. These are the strategic starting points for Huawei to increase scale and inspire passion. (Ren Zhengfei: What Can We Learn from the American People?, Improvement Issue No. 63, 1998)

If we can stay ahead of our competitors and control our costs after we seize a large market share, we might be able to maintain that share of the market. The costs I am talking about are not just the costs for technologies and products. If we can't control costs or hold on to our market share, our competitors will easily catch up even if we are achieving technological breakthroughs. Like the "mile-a-minute weed" up this space will lock in this industry. (Ren Zhengfei: Speech at the 2008 Mid-year Report by Regions to the EMT, EMT Meeting Minutes No. [2008] 028)

\section{Centering our business operations on profits, but not pursuing maximum profits}

For many years, Huawei's growth has been oriented towards sales. In a bubble economy, this growth model is understandable. This is what happens in the real estate market. When prices are very high, whoever controls more land will earn more. In Huawei's early years, our net profit reached $23 \%$. At that time, as long as we won a contract, we would turn a profit. This is why we have developed a sales-focused culture. However, this culture hasn't changed with the times. We must change now. During this historic period, selling more is no longer enough. We need to increase our operating efficiency and project management capabilities. We need to shift our focus towards three things: sales revenue, contribution gross profits, and cash flow. These are necessary for us to maintain a balance in the long run. (Ren Zhengfei: Adapting the Manager Appraisal System to Challenges Facing the Transforming Industry, Huawei Executive Office Speech No. [2006] 036)

In our first two decades as a company, the market was huge and profits were high. At that time, we focused on scale because it guaranteed profits. But things are changing. Now, when we assess the performance of each representative office, region, and product line, we focus more on positive cash flow, positive profit margins, and improvements in per capita efficiency. I believe significant changes will take place over the next three

\footnotetext{
4 "Mile-a-minute weed" is an extremely vigorous plant that can survive and grow quickly even in harsh conditions.
} 
years. If we continue to focus on scale, the company will spin out of control. (Ren Zhengfei: Remarks at a Meeting with Senior Managers at a Project Management Summit, Huawei Executive Office Speech No. [2009] 007)

The paramount goal of a company is to serve its customers and earn profits. After 20 years of development, we are finally able to say that our business operations are centered on profits. However, there are shortterm, mid-term, and long-term profits. There is no rule for when profits need to be gained. Profits gained this year are profits, and profits that take 10 years to gain are still profits. Being profit-centered is an important aspect of our management transformation. The entire organization and the people responsible may experience significant changes because of our emphasis on profits. So why am I so confident? I think the ultimate result we want from the transformation is that Huawei will be able to perform a little bit better than it did the day before. This slight difference in performance is what will enable us to survive. Sometimes, the difference between life and death might be only a second or two. (Ren Zhengfei: Speech at the Regular Meeting of the Reserve Pool, 2009)

Maximum profits are not what we pursue. In fact, maximizing profits will bleed the future dry, which in turn will harm our strategic position. (Ren Zhengfei: Speech at the EMT ST Meeting, 2010)

When Huawei was still a small company, we saw profits each year despite our goal to become a big company. If we didn't have money to distribute, the company would have collapsed long ago. Every one of you wants to grow our company into those like Cisco and Apple, and every one of you speaks louder the richer you become. It would have been fine if we just focused on what we had and made breakthroughs. But we insisted on becoming a large world-class company. That is why we have unfolded all of our businesses. However, we failed to do a good job in some key areas. We must not continue to expand to areas where we can't create value. We must focus on creating value. (Ren Zhengfei: Speech at the EMT ST Meeting, 2012)

\section{Cash flow is the lifeline of a company}

I once took our senior executives for a visit to the Hakka fortified houses. How were the Hakka people able to safeguard their fortified houses? Why were these big houses able to survive? The key lies in the fact that every big house had a well that functioned effectively. This is like cash flow. Our senior managers must be fully aware of the importance of cash flow. There is no sign of collapse for Huawei even today. This is because 
we've always had cash flow. We can store materials like food. However, without water, we won't be able to survive. The biggest characteristic of fortified houses is that each of them has a well. Castles outside of China all needed water supply, as it was crucial to both war and life. At Huawei, this well is the cash flow in our financial management. (Ren Zhengfei: Speech at the Third Quarter Meeting Regarding Marketing in China, 2004)

The biggest danger in the future will lie in cash flow. We must pay great attention to this. If we encounter a big problem in the future, that will be a drain on cash. This is a bottleneck for any company's survival, and many companies in the industry have collapsed because of this problem. What happened to the company D'LONG International Strategic Investment? It went bankrupt because a soft landing was impossible for many of its projects due to a drain on cash. All the banks asked the company to pay back their loans, which disrupted the company's chain of operations. This is why we say "cash is king". Therefore, if we collapse, it will probably be caused by a drain on cash. We won't collapse because of lack of profits. Without profits, we can sell our buildings or land. That will sustain us for several years. But without cash, we will quickly go bankrupt. (Ren Zhengfei: Strengthening Payment Collection and Improving Cash Flow-Speech at the EMT ST Meeting on February 28, 2006, Huawei Executive Office Speech No. [2006] 007)

Only robust and balanced financial results will be able to support the company's long-term survival and development

We should not overemphasize any single indicator in our appraisals, because doing so will not guarantee our company's sustainable development. If we only focus on sales revenue, some regional offices and product lines will do whatever they can to get strategic subsidies and price cuts from the company. We usually see this behavior in incompetent sales people and managers who can only sell products at low prices. Using this approach, the more we sell, the sooner we will perish. (Ren Zhengfei: Speech at the Mid-year Market Conference, Huawei Executive Office Speech No. [2006] 036)

We must continue to base our performance appraisals on factors such as sustainable and profitable growth, profits, cash flow, and per capita efficiency improvements. (In areas where operations are mature, we can use total compensation packages as the basis of this accounting.) In cases where departments fail to exceed the average score for corporate-level per capita efficiency improvements, the heads of areas, regions, representative offices, product lines, and other departments will be held accountable. 
Departments that exceed the average score must be ranked by positive profits, positive cash flow, and strategic goal attainment; senior managers that rank the lowest will be removed from their positions. This is different from our past practice of not penalizing senior managers and will allow us to assign people with successful field experience to our HQ. (Ren Zhengfei: Who Calls for Artillery and How Do We Provide Timely Artillery Support?Speech at the Awards Ceremony of Sales \& Services, Huawei Executive Office Speech No. [2009] 001)

The purpose of sales is not merely to sign contracts. Any exciting opportunity has to generate revenue, and all revenue has to bring profit and cash. Otherwise, temporary success will lead to the company's demise. (Ren Zhengfei: Guidelines on the Analysis of the Business Environment and Key Business Strategies, Corp. Doc. No. [2012] 081)

Huawei is an asset-light company, and doesn't have the capacity or experience to manage assets. If we own heavy assets, our fluidity will become increasingly poor. Then we will face the problem of demise, not profitable and sustainable growth. (Ren Zhengfei: Comments at a Meeting with Sales Financing Experts, Huawei Executive Office Speech No. [2012] 025)

"With survival as our bottom line, we aim to achieve profitable growth and healthy cash flow, and avoid asset-heavy operations." This goal should be made clear and we need to focus on achieving this goal over the next two to three years. (Source: Minutes of the Report on the 2016 Work of the Finance Committee, Board of Directors Meeting Minutes No. [2017] 006)

\subsubsection{Continuously Improving Huawei's Core Competencies}

Increasing forward-looking, strategic investments to build the company's future technological advantages and lead industry development

Business operations and management should center on our core competencies, not on short-term interests. Huawei will never do anything that is not conducive to enhancing our core competencies. When faced with opportunities outside the scope of our core competencies, we can resist the temptation. Some might say that we've let so many opportunities slip through our fingers in an attempt to maintain a strong hold on our core competencies. But I would argue that, without our core competencies, we would lose the opportunity to develop entirely. Sure, we have a lot of opportunities right within our grasp, but only by approaching them with caution can we achieve something that no one else could possibly achieve. 
We only have one standard for ourselves: Continue to improve upon our core competencies. With them, we can do many, many things. Without them, we can't achieve anything. This is why we're constantly trying to cut down on superfluous activities. (Ren Zhengfei: Huawei's Opportunities and Challenges, 2000)

We must invest more in strategic goals. Our investments today can only produce effects in two years' time. If we reduce investment today, we will lack the seeds and fertilizer we will need when spring comes. (Ren Zhengfei: Speech at the CEO's Staff Team Meeting, 2001)

We will increase forward-looking, strategic investments, and build up our technological advantages for the future to lead industry development. We must increase our technology-centric strategic investments to maintain a leading position in the industry. After all the talk about customer centricity, it is possible that we go from one extreme to the other and ignore our forward-looking technology-centric strategy. In the future, our concept of technology centricity will be intertwined with our concept of customer centricity. We will be customer-centric when developing products, and technology-centric when developing next-generation architectural platforms. (Ren Zhengfei: Guidelines on the Analysis of the Business Environment and Key Business Strategies, Corp. Doc. No. [2012] 081)

Moving forward on two wheels - technological innovation and management transformation - to drive the ongoing improvement of the company's core competencies

Short-term improvements to management should be guided by the long-term goal of enhancing the company's core competencies. With this in mind, we will not get lost in the midst of short-term management improvements, and our short-term and long-term goals will not contradict each other. As a result, our core competencies will improve, and we will discover what we need to survive and what value our survival brings. (Ren Zhengfei: Survival Is Fundamental to an Enterprise, 2000)

What can help us to survive a "hard winter"? The answer is high quality and low costs. Whoever delivers the highest quality at the most affordable price and is the most responsive to customer needs will be able to survive the winter. Therefore, the top priority for managers in charge of R\&D is to improve quality and reduce costs. Only when they have achieved these two things can they start to explore the direction of technological innovation. The three pillars that support technological 
innovation are: quality, cost, and time. Technological innovation that does not satisfy these conditions is worthless. We should never innovate for the sake of innovation. We must be both bold and cautious when doing research. We must also be bold enough to spend money yet cautious about quality and technological validation. (Ren Zhengfei: Speech at a Meeting with the RoD Managers of Huawei Technologies and Avansys, 2001)

How can we succeed in our globalization and maintain our competitive advantages? Huawei's core values have told us what our goals, strategies, and approaches are. We have survived through dedication and technological innovation. Isn't there an end to technological innovation? Will Moore's law carry on forever? Can we win in all markets with the same approach? In my opinion, when wired and wireless broadband access reaches a certain bandwidth, and have a certain degree of coverage, innovation in network technology will slow down. At that time, companies that have a very large market presence will be managed effectively and that can provide low-cost high-quality services will be able to survive. Huawei has to become such a company before a decline. In the past ten years, we have strived to change ourselves, modestly learn from Western companies, improve efficiency, develop an exceptional human resource management mechanism, and motivate all our staff to remain dedicated. This is the only way for us to survive. As long as we are not complacent, we will surely become a winner over the long term. (Ren Zhengfei: The Market Economy Is Best for Competition; Economic Globalization Is Inevitable-Speech at the Commendation Meeting of Finance, Huawei Executive Office Speech No. [2009] 005)

We have two principles for innovation. First, we must emphasize value. We must not innovate for innovation's sake; rather, we must innovate to create value. Second, we must be more tolerant of failures in innovation. (Ren Zhengfei: Speech at the Meeting with Staff from the 2012 Laboratories, Huawei Executive Office Speech No. [2012] 035)

What is the downside of engineers being managers? Engineers-turnedmanagers tend to neglect management and emphasize technological innovation so much that they end up making products that no customer wants. We should not always prioritize technology. We must also emphasize management and shift our focus from technology to business. A project manager must be a business leader, not a technical expert. (Ren Zhengfei: Speech at the EMT ST Meeting, 2012) 


\subsubsection{Building a Healthy and Friendly Business Ecosystem}

We need to possess strategic thinking when building a business ecosystem

As Huawei continues to grow, it may be impossible to always have friends around us; we do have foes, as we may have caused the collapse of many smaller companies. We need to change this situation; we need to achieve a win-win scenario through open collaboration. We have turned some friends into foes during the past 20 years; in the next two decades we will strive to turn foes into friends. When we have numerous friends across the value chain, we will surely achieve even greater success. (Ren Zhengfei: Customer Centricity, Increased Platform Investments, and Open Collaboration for Shared Success-Speech at the 2010 PSST Managers' Meeting, Huawei Executive Office Speech No. [2010] 010)

Any strong man is balanced. Can we survive when we become extremely strong, but have no friends around us? No. Why should we force out other players in order to dominate the market? Many people throughout history wanted to conquer the whole world, but in the end they perished before their goals were achieved. Huawei will surely fail if we have the same mentality. Why shouldn't we work with our partners, especially strong ones? We must not be so narrow-minded as to force out other players. Rather, we should cooperate with our peers while competing alongside them, as long as such cooperation is in the interest of both parties. (Ren Zhengfei: Customer Centricity, Increased Platform Investments, and Open Collaboration for Shared Success-Speech at the 2010 PSST Managers' Meeting, Huawei Executive Office Speech No. [2010] 010)

As our business continues to grow and change, the business environment will become increasingly tough. We must have measures in place to help us handle tough situations. Although we are already very strong, there are still many problems within our organization. We must be strong internally and soft externally and learn to make concessions. In addition, we must avoid being arrogant and learn to appropriately handle internal and external relationships. What looks strong on the surface is not always strong throughout. (Ren Zhengfei: Success Is Not a Reliable Guide to Future Development-Speech at the Huawei Market Conference on January 17, 2011, Huawei Executive Office Speech No. [2011] 004)

Huawei's future success relies on two factors: One is organizational capabilities and vitality; the other is a favorable business ecosystem. Will 
we have the capacity to run a company with revenue of US\$100 billion? Will we have the vitality to cope with future challenges? Will the business ecosystem be tolerant of us and allow us to become big and strong? What measures will we take to improve the business ecosystem? (Ren Zhengfei: Do Not Expand Blindly and Do Not Assume That We Are Already Strong Enough, Huawei Executive Office Speech No. [2012] 006)

In this era of heroes, we must dare to lead on a global scale; but once we establish our advantages, we cannot afford to make enemies. We must instead cooperate with others. Someone asked me, "What is your business philosophy?" I replied, "We do not have a business philosophy. We simply serve our customers." (Ren Zhengfei: Speech at the Corporate Strategy Retreat, 2015)

\section{Exchanging land for peace}

Managers at Huawei do not have to cater to the needs of employees, but should adopt appropriate methods to achieve company goals. Temporarily, we may need to sacrifice our short-term interests, but in the long run, our company will grow. (Ren Zhengfei: Huawei's Hard Winter, 2001)

When we were cooperating with a world-class company, which was also one of our all-around competitors, I told them I was a disciple of Yitzhak Rabin, and that we should be interdependent and seek the help of each other to coexist. I mentioned my respect for Rabin to illustrate our longterm strategic relationship with competitors. (Ren Zhengfei: Huawei's Hard Winter, 2001)

About seven or eight years ago, we began to implement a "land for peace" strategy, seeking to cooperate with competitors at the cost of our market share. This cooperation complements our strengths and creates greater value for customers. Also, we have become more recognized, and our competitors have begun to treat Huawei as their friend. While we vie with competitors for the opportunities to provide customers with superior services, we collaborate with competitors to drive down product development costs. This change in the paradigm has added fuel to our growth momentum and will significantly reshape our future development. (Ren Zhengfei: Seeing the Situation Clearly and Accelerating Organizational Building and Reserve Pool Development to Embrace Huawei's New Development-Speech at a Meeting for $H R$ Directors, 2005) 


\subsubsection{Pursuing Huawei's Long-Term Value}

Value reflects an enterprise's current and potential capabilities to make profits

Although a product may not be profitable at first, it can still become profitable in the future. We must adopt a long-term profitable strategy for products that are not yet producing profit in the short-term. The key is to set up a point of marginal cost so that once we exceed that point, we will become profitable. (Ren Zhengfei: Speech at a Briefing on Developing the IP Microwave Business, 2009)

During our current restructuring, we should prioritize market opportunities first, and then per capita efficiency. If we only emphasize per capita efficiency, based on our business performance this year, per capita efficiency will increase as long as we don't increase the size of our workforce. But we won't have achieved sufficient growth. To truly increase per capita efficiency, we need to first guarantee sustainable and profitable growth - a mechanism centered on self-coordination. We can't focus single-mindedly on per capita efficiency, or we will definitely fail. We need to have a strategic mindset - focus our attention on growth, as well as the total amount of profit we generate - and then we can assess per capita efficiency. Otherwise, we're doomed to failure. (Ren Zhengfei: Speech at the Regular Meeting of the Reserve Pool, March 25, 2009)

We must focus on our core business. Value - not technology - must be at the center of everything we do. (Ren Zhengfei: Speech at a Work Report of the Network Energy Product Line, Huawei Executive Office Speech No. [2012] 043)

Huawei's business model: always staying hungry, not seeking to earn big money

In this era, it doesn't matter if we cannot influence market demand. Rather, we must be able to adapt to changes. Many of our existing assets are a legacy of the voice era. Our success over the past two decades will not ensure our future success. We need to put our past success behind us and move forward. I don't think we should consider technology to be a threshold, because competitors will catch up with us sooner or later. Customers might not remain loyal to us all the time, because we might not treat them the same as time goes by. What actually matters, in my opinion, is the business model. Why do I insist on earning small money, instead of big money? It's because of our business model. We have managed to catch up with other vendors because many of them decreased their investment in areas that generated lower profits. If we continue to earn small money after we 
become the industry leader, it will be impossible for other players to earn big money in the industry. Will they remain dedicated if they can only earn small money? If not, we will remain the industry leader. If we always stay hungry and do not seek to earn big money, we will keep earning small money and survive. If we give employees decent pay, they will stay and we can keep the company running. If we only focus on short-term interests and seek to earn big money, we will be digging our own grave. Although a company's survival depends on many different factors, I think that maintaining sustainable and profitable growth and providing quality services are the most important. (Ren Zhengfei: Speech and Comments at the Carrier BG's 2013 Strategy Retreat, Huawei Executive Office Speech No. [2014] 016)

Huawei has been swayed many times in the past. I think that to succeed, one has to focus on the things that one is good at. Just now, a colleague said making chips doesn't make much money. Those who make semi-conductors earn a lot of money. But those who earn big money won't be able to sustain it, because people will become jealous of the profits and want to get in the game. What about earning modest profits? We work hard, but our profit margins are lower than those of real estate companies. It would be unfair if we perished first. When I talked to the vice president of the EU, he asked me how Huawei could develop when the global economy is in such bad shape. My answer was that, first of all, we are dealing with small amount transactions, which are not particularly influenced by economic crises. For example, if you owe me money, I still have to make a call to ask you to pay me back. That telephone call costs a small amount of money. Secondly, our profit rate is lower than restaurants or real estate companies. Since we can survive with such a low profit margin, we won't collapse that easily. While the whole world is anxious, the management team of Huawei is not. We are going on with the transformation. Although the overall economy is not good, we have still managed to offer our employees pay raises over the past few years. How have we managed to remain stable? The answer is that we insist on earning small money. (Ren Zhengfei: Speech at the Meeting with Staff from the 2012 Laboratories, 2012)

\subsubsection{Sharing Gains Based on the Capital and Labor Invested}

Cooperation between people is actually based on interest distribution. If our initial aim were to get rich alone, we would have fewer partners, our organization would be less effective, and our profits would be lower. In 
that case, we would have a higher distributable percentage out of a smaller sum. When these two factors are multiplied, the outcome would be small. Our aim is to make the overall pie bigger and decrease our own slice of the pie. This adheres to the principle of interest sharing. (Ren Zhengfei: Speech Regarding Corporate Organizational Goals and System Blueprints for the Future, 1994)

Resources can be exhausted; only culture endures. Huawei does not have any natural resources to depend upon. What we do have is the brainpower of our employees. This is our oil, our forests, and our coal. Human ingenuity is the creator of all wealth. (Source: The Huawei Charter, 1998)

We must establish a value distribution system where the income of each employee is linked to the company's overall performance. When the company performs well, we must dare to expand and share risks together. When the company experience difficulty, we need to get through the hard times together. In this way, we can share the pressure among all employees across the company. (Ren Zhengfei: Key Points for Management, 1999)

To achieve growth, an enterprise must create results for its customers, capital providers, and employees. Therefore, it is essential to satisfy customer needs, and cultivate employees who are passionate and work hard to meet these needs. We should base salaries on employees' real contributions and potential to continually contribute, and base bonuses on shortterm contributions. We should also emphasize individual contributions to capital. Any increase in headcount should be accompanied by added value. An enterprise must satisfy its customers, as this is the basis for its survival. It must also satisfy its shareholders, as this is the purpose of their investment. The enterprise must satisfy its value contributors, and value the contributions of dedicated employees, as they are the driving force behind sustainable growth. (Ren Zhengfei: Guidelines for Human Resources Management Transformation, 2005)

Who will Huawei recognize, dedicated employees or shareholders? People outside Huawei say that Huawei shares are valuable because Huawei employees are dedicated. If no one works hard, these shares will become valueless. Your efforts are saving the company and ensuring the interests of financial investors. Financial investors should be rewarded adequately, but dedicated employees should receive higher rewards. This is a reasonable value distribution mechanism. (Ren Zhengfei: Remarks at a Meeting with Members of the Project \& Financial Management Enablement Program for High Potentials, Huawei Executive Office Speech No. [2014] 054) 
One employee posted an article from an external critic on our Xinsheng Community, saying, "If Huawei fails to make profits continuously, a bubble will emerge in its Restricted Phantom Shares, which will burst sooner or later." This article speaks the truth. Therefore, Huawei must work hard to improve itself, focus on strategy, simplify management, reduce redundancy, and dismiss underperformers. This is the only way for us to inspire passion across the company. Similarly, public companies will collapse if they don't make profits. Without profit, private companies won't grow either. We don't have a different fate. What we can do is work hard. (Ren Zhengfei: Comments to Staff of the Enterprise BG, Huawei Executive Office Speech No. [2014] 006)

Our Restricted Phantom Shares plan was approved by the Chinese government and is therefore legal. Several top government officials have asked about this plan and wondered whether it can promote industry development. Even though we are abiding by the law, any investment has risks. We bundle our risks with employee dedication. If employees are confident in their own dedication, then they voluntarily buy company shares. Of course, they can choose not to buy. If they are worried, any of them can withdraw from the plan completely, during the period of the company's steady development. However, once they withdraw, they will not be allowed to buy back their shares. If they want to buy shares later, they have to follow the share distribution plan, which is based on contributions, and this has ceilings. (Ren Zhengfei: Comments to Staff of the Enterprise BG, Huawei Executive Office Speech No. [2014] 006)

Huawei has been successful over the past 20 years because it has implemented a value sharing mechanism based on the capital and labor employees invest. This mechanism should be extended to also include our suppliers and customers. The ultimate result is that we share the world market. (Ren Zhengfei: Remarks at the Strategic Reserve's Oath-taking and Awards Ceremony, Huawei Executive Office Speech No. [2015] 083)

Yang Lin: Just now you mentioned Huawei's mechanisms. There are many discussions in China about Huawei's mechanisms and corporate culture. May I hear your own perspectives on this? Ren Zhengfei: Our culture is very simple: staying customer-centric and inspiring dedication. In this world, our customers treat us best, so we need to devote ourselves to serving them. As we want to earn money from our customers, we must treat our customers well, and make them willing to give us their money. In this way, we establish good relationships with them. How can we serve our customers well? By working hard despite all the hardships we might 
encounter. We need to motivate our dedicated employees and set a reasonable ratio between gains from capital and labor. (Source: A Chat in the Garden with Huawei Founder Ren Zhengfei, Huawei Executive Office Speech No. [2015] 098)

Yang Lin: Huawei has achieved great success, especially in Europe. How has Huawei emerged from a small unknown Chinese company to a top player in the European market? How has Huawei eaten away the market share of its competitors, including established companies like Nokia and Ericsson? Ren Zhengfei: Actually, you're wrong. You should say how we have worked together with these companies to contribute to the world. The information society is developing faster than our own capabilities. If this weren't the case, we could be playing golf and relaxing in cafés. During this period, our global peers have also grown, and the apple has become too big to peel. Our strategy is to collaborate and grow to meet social needs. Our value sharing mechanism has allowed us to share our gains from capital and labor with our employees, which is now gradually extending to sharing success with our customers and suppliers. In addition, we are cooperating with world-leading companies to formulate standards and set roadmaps. Together, we can make a greater contribution to society. We are not so insular as to want to wipe others out. The reason that some companies burn money is to dominate the market when their competitors have no money to burn. We don't intend to dominate the market. We haven't eaten away at our competitors. Neither have we ever intended to do so. Instead, we have tried our utmost to help them become strong. For example, we are very happy to learn that Nokia will merge with AlcatelLucent. I think Nokia's spirit of dedication is stronger than any other company. That's why it is able to return to the world stage. We will enhance cooperation with these companies to serve society. (Source: $A$ Chat in the Garden with Huawei Founder Ren Zhengfei, Huawei Executive Office Speech No. [2015] 098)

We have only one core value at Huawei, which is contributing more to earn more. The Contribute and Share system applies to all dedicated employees, no matter what positions they hold. Driven by benefits, the company will move forward. Due to a lack of attention, the compensation of staff in our visa handling department used to be very low. In the future, we will raise the compensation level so that we are able to attract more outstanding people to help us deploy more of our staff in field offices. Monetizing visa processing will motivate staff to work harder. (Ren Zhengfei: Speech at the Annual Meeting of the Employee Relationship Dept, Huawei Executive Office Speech No. [2016] 058) 
I view core values like this: Each element that contributes to value creation should be rewarded accordingly. "Freedom, equality, and fraternity" are all very good ideas. However, it is unclear who will actually make the "cake". Without a cake, how can you ensure "freedom, equality, and fraternity"? Many people say that network equipment will become white boxes, and will be very cheap. However, who will cook the "free lunch"? And who will maintain these white boxes? Can white boxes be of high quality and with good maintenance services? If an element contributes to value creation but is not rewarded, it will not be sustainable. A free lunch does not comply with the rules for the market economy. If people cannot make money in one domain, they will leave and go somewhere else. This kind of innovation concerns business model innovation, whereas the US tends to focus on technological innovation. (Ren Zhengfei: Remarks at Meetings with Huawei Fellows, Huawei Executive Office Speech No. [2016] 069)

Capital may play a role in creating our world, but labor still plays the biggest role. We have benefited from reading communications standards in the past 20-plus years and have instilled them into the brains of our employees. We "weighed" each brain and distributed company shares accordingly. This helped us develop a new mechanism. Those who read these standards are very capable. Even if several people left, our standards system still remains. If our company collapses one day, we will no longer have the same standards as before even if we gather everyone together again. This is because standards can sustain only when they have life. Because our management and standards systems are lifeless, without support from people, these systems would be useless. So, we must not allow Huawei to collapse. Otherwise, the management system we have spent more than ten billion dollars developing over the last few decades will be useless, and our understanding of technical standards will also be of no use. (Ren Zhengfei: Remarks at Meetings with Huawei Fellows, Huawei Executive Office Speech No. [2016] 069)

Over the past 28 years, we have adhered to working together towards the same goal and receiving income from the same source, and investing long-term to make strategic breakthroughs. We have also adopted a value sharing mechanism for capital and labor, and collective dedication is our unique competitive advantage. (Ren Zhengfei: There Will Not Always Be Flowers Along the Road Abead-Speech at the HI Huawei Market Conference, Huawei Executive Office Speech No. [2016] 079)

There are rumors circulating online that Huawei employees retire at the age of 34 . If this is the case, I wonder who will pay for their pensions. 
Huawei doesn't have a pension fund. The company purchases social insurance, health insurance, and accidental injury insurance for employees. Concerning retirement, you have to comply with national policies. Even if you leave the company, you still have to pay the premiums; otherwise, your insurance will be cut off. You won't receive your pensions if you don't comply with national policies. Of course, you could try to ask the heroic and dedicated employees working in Tibet or Bolivia, or in regions subject to war and disease, if they are willing to pay for your retirement. After all, employees working in such regions have higher bonuses. They struggle through rain and ice, and endure bitter hardship. Will they give you some money for your retirement? Huawei doesn't have much money. The company will collapse if we do not remain dedicated. We won't pay anything to people who are not dedicated. Do you really think it is realistic that at thirty-something years old, in the prime of your life, you don't have to work hard, and can just lie on your bed counting money? (Ren Zhengfei: Speech at Meetings in Thailand with Regional Supervisors and in Nepal with Staff, Huawei Executive Office Speech No. [2017] 026)

We need to gradually increase our efficiency, and ensure that our spending on people grows more slowly than sales revenue and profits. We expect three people to do the work of five and earn the income of four. We need to enhance the Contribute and Share system, and develop a team with collective interests and common beliefs despite having diverse cultural backgrounds. (Ren Zhengfei: Huawei's Success Is Also the Success of Our HR Policies-Speech at a Dinner with Some CHR Staff, Huawei Executive Office Speech No. [2017] 037)

\subsubsection{Passing Market Pressure Down Through Each Layer of the Company to Make Sure Our Internal Response System Remains Active}

Core values can be passed down only after they are turned into a benefit-driven mechanism

All enterprises are benefit-driven. This requires a fair value distribution system preceded by objective value assessments, which in turn need to be underpinned by a positive corporate culture. This is necessary to ensure that outstanding people who have made contributions to the company will be paid fairly. (Ren Zhengfei: Seizing Opportunities, Adjusting Management Systems, and Meeting Challenges, 1997) 
"Staying customer-centric, inspiring dedication, and persevering" is a benefit-driven mechanism. To sustain our culture of inspiring dedication, we must reward our dedicated employees. We will not forget those who have a sense of mission and proactively contribute. That might be our corporate culture. We cannot build our culture and make it sustainable with empty talk. Instead, we must incorporate this culture into our appraisal system. (Ren Zhengfei: From "Philosophy" to Practice-Speech at Huawei Annual Management Conference 2011, Huawei Executive Office Speech No. [2011] 016)

Other companies may be people-centered, but our company focuses on dedicated employees. We are increasing our market share through hard work, not through a monopoly. Therefore, we distribute value to our dedicated employees. We are opening our doors to all kinds of talent. We can increase the size of the pie only by uniting as many people as possible. As long as you work hard, the slice of the pie you get will only increase. Don't be afraid that it will be snatched away by a newcomer who's been here only two months. If we are open-minded like this, we will grow even stronger. (Ren Zhengfei: Speech at a Meeting with Elite Teams at the Training Camp on July 23, 2013, Huawei Executive Office Speech No. [2013] 174)

We must widen the gaps in employee compensation based on the value that each employee contributes. We must fully fuel the engines in the organization so that they can drive the train to run faster and deliver more. To truly live out our core values, we must have a group of people who set the example. Employees' compensation is not based on their scope of management; it has to be based first and foremost on contributions, results, and responsibilities, and second on the spirit of dedication. (Ren Zhengfei: Applying the Spirit of the Tortoise to Catch up with the Dragon Spacecraft-Speech at the Huawei Annual Management Conference, Huawei Executive Office Speech No. [2013] 255)

Huawei protects the interests of its dedicated employees. If you are tired and want to retire, we are there for you. We must not say that previous dedicated employees are no longer entitled to company benefits. If we do, who will be willing to fight in the battlefield? But who will be willing to work hard if we give more to retired employees and less to dedicated employees? I will also retire in the future, so I should be among those who support the policy of giving more to the retired employees and ask you to do more work, so that I can get more money. But wouldn't you be a fool 
to accept that? So, our core values won't change much. Those who circulated this rumor must be underperformers. (Ren Zhengfei: Remarks at a Meeting with Members of the Project \& Financial Management Enablement Program for High Potentials, Huawei Executive Office Speech No. [2014] 054)

Our assessment system should focus on results and responsibilities, and we should motivate heroes in a timely manner. We should dare to fast track outstanding employees and widen the income gap between high performers and low performers. First, our incentives for heroes should be offered promptly. This means that we should focus on goal fulfillment and must not appraise employees based on the leadership model. Those who have achieved success in a project should be given an incentive. As to whether they should become managers, we need to measure them against the leadership model. Currently, there is a tendency of using key performance indicators for every type of assessment. What does success have to do with these indicators? Those who achieve success are heroes. We should reward them for their contributions, and should not consider irrelevant shortcomings. But we will take their shortcomings into account when we consider promoting them to managerial positions or raising their personal grades. Second, we should dare to widen the income gap between high performers and low performers, and dare to fast track employees who have made outstanding contributions. Outstanding employees should be rewarded more and fast tracked. If we don't widen the income gap, outstanding seeds will not be able to grow. If these employees are suppressed and not promoted, there will be backlash and the morale of their teams will be low. Strong teams are made in battles. Once a team achieves success, promotions should quickly follow so that morale will be boosted and the team will become even stronger. We need to select several outstanding employees as role models, to motivate others to fight in the battlefield and outperform the role models. This will boost morale. Those who don't make progress, fall behind, or perform poorly will gradually be removed. (Ren Zhengfei: Speech at a Meeting with Employees of the Central Asia \& Caucasia Region, Huawei Executive Office Speech No. [2016] 063)

Transferring market pressure to every process and every employee to inspire passion across the organization

At its current stage of development, the problems Huawei faces will only continue to grow. We will either stagnate and die off, or work harder, achieve more, and stand shoulder-to-shoulder with other great companies 
of the world. Managing a company is like rowing upstream: If we don't advance, we will be driven backwards. We need to instill a sense of urgency into every single Huawei employee. (Ren Zhengfei: Toasting Those Who Succeed and Offering a Helping Hand to Those Who Fail, 1997)

There's no way back; we have to burn our boats. We need to transfer a sense of urgency and pressure to every employee. We need to pass market pressure down through each layer of the company to make sure our internal response system remains active. (Ren Zhengfei: How Long Can Huawei Survive?, 1998)

Outside China, we were often offered opportunities to participate in telecom privatization projects, but we didn't. Because of this, we may encounter greater difficulty in selling equipment in the future. This has forced us to develop products that are of the best quality, with the best performance and service, but at the lowest costs. If we fail to do this, we will find it hard to sell them. Poor performance in any segment will be subject to criticism from other segments. Through this transfer of market pressure, we can ensure our internal operations are always vigorous and activated. Placing ourselves in a desperate position can force us to become a world-class equipment provider. (Ren Zhengfei: How Long Can Huawei Survive?, 1998)

Junior and middle managers should have a sense of urgency. What does it mean by this? It means $10 \%$ of managers will be removed from their positions each year. As a manager, you have been given trust and opportunities. If you fail to put these to good use, the company will have no choice but to remove you from your position. We must resolutely remove unqualified managers. Only in this way can we rank and screen managers, drive them to remain passionate under pressure, and help our teams maintain their effectiveness. (Ren Zhengfei: Staying Customer-centric, Inspiring Dedication, and Persevering Are Key to Our Success-Speech at the 2010 Huawei Market Conference, Huawei Executive Office Speech No. [2010] 002)

Our future value assessment system must be oriented towards business success. Managers who create long-term losses for the company must be removed from their positions, along with personal grade decrease and pay cuts, to deter others from following in their footsteps. Even if they are outstanding seeds, why not demote them and place them in the Strategic Reserve as ordinary employees? They can rise again after further contributions are made. First, their pay needs to be lowered and positions adjusted. After they do a good job, they can rise again. Therefore, 
managers with poor business performance need to be replaced. If managers are weak, the entire team will be weak. Managers who fail to make strategic contributions must not be promoted. (Ren Zhengfei: Growing from a Soldier to a General Within Three Years, Huawei Executive Office Speech No. [2014] 031)

Open Access This chapter is licensed under the terms of the Creative Commons Attribution-NonCommercial-NoDerivatives 4.0 International License (http:// creativecommons.org/licenses/by-nc-nd/4.0/), which permits any noncommercial use, sharing, distribution and reproduction in any medium or format, as long as you give appropriate credit to the original author(s) and the source, provide a link to the Creative Commons licence and indicate if you modified the licensed material. You do not have permission under this license to share adapted material derived from this chapter or parts of it.

The images or other third party material in this chapter are included in the chapter's Creative Commons licence, unless indicated otherwise in a credit line to the material. If material is not included in the chapter's Creative Commons licence and your intended use is not permitted by statutory regulation or exceeds the permitted use, you will need to obtain permission directly from the copyright holder. 